\title{
Effectiveness of peers in delivering programs or motivating older people to increase their participation in physical activity: Systematic review and meta- analysis
}

Running title: Do peers increase physical activity

\section{Authors}

Elissa Burton, Kaela Farrier, Keith D Hill, Jim Codde, Phil Airey, Anne-Marie Hill,

Elissa Burton, Institute for Health Research, The University of Notre Dame Australia, PO Box 1225, Fremantle, Western Australia, Australia 6959.

Kaela Farrier, School of Physiotherapy and Exercise Science, Curtin University, GPO Box U1987, Perth, Western Australia, Australia 6845.

Keith D Hill, School of Physiotherapy and Exercise Science, Curtin University, GPO Box U1987, Perth, Western Australia, Australia 6845.

Jim Codde, Institute for Health Research, The University of Notre Dame Australia, PO Box 1225, Fremantle, Western Australia, Australia 6959

Phil Airey, Council on the Ageing (WA), Perth, Western Australia.

Anne-Marie Hill, School of Physiotherapy and Exercise Science, Curtin University, GPO Box U1987, Perth, Western Australia, Australia 6845. 


\section{Corresponding Author}

Correspondence concerning this article should be addressed to Dr Elissa Burton, Institute for Health Research, The University of Notre Dame Australia, PO Box 1225, Fremantle, Western Australia, Australia 6959.

Email: elissa.burton@nd.edu.au

Phone: +61892664926

\section{Disclosure statement}

The authors report no conflicts of interest for this project.

\section{Acknowledgements}

This research was funded through the Australian Government's Collaborative Research Network (CRN) program. The funder had no role in the study design, data collection, analysis and interpretation of the data, writing the report or the decision to submit the article for publication. The authors would like to thank Eileen Boyle for acting as the third assessor for the non-randomised studies. 


\title{
Effectiveness of peers in delivering programs or motivating older people to increase their participation in physical activity: Systematic review and meta-analysis
}

\author{
Running title: Do peers increase physical activity
}

Keywords:

Mentor, buddy, ageing, exercise, older adults. 


\begin{abstract}
The objective of this systematic review and meta-analysis was to evaluate the effectiveness of peers to deliver programs or encourage older people to be physically active and improve physical outcomes. Peer reviewed articles published in English between January 1976 and June 2016, retrieved from six databases according to the predefined inclusion criteria were included. Where possible results were pooled and meta-analyses conducted. Eighteen articles were included in the review, a total of 3,492 intervention participants, average age 66.5 years and $67.1 \%$ were female. Overall, study quality was medium to high. Interventions mainly included resistance, flexibility and cardiovascular training, however there was one aquatic exercise group. Eight studies were delivered by peers and five utilised peer support, which included advice and being positive but was not directly linked to an exercise intervention. While 16 of the 18 studies reported improvement in levels of physical activity and/or noted physical benefits by peer involvement, the meta-analyses findings supported the control groups for the six minute walk test (favoured intervention) and the timed-up-and-go (favoured controls) tests. Meta-analyses data were limited due to studies using a variety of measurement tools and included predominantly small sample size studies. Findings from this review suggest exercise programs involving peers can promote and maintain adherence to exercise programs. However, results are inconclusive as to whether peers have a positive effect on improving physical function for older people.
\end{abstract}




\section{Introduction}

Being physically active at any age has many health benefits across the physical, mental or social domains (Warburton, Nicol, \& Bredin, 2006). As people age there is a tendency to reduce the amount of exercise they undertake each year (Australian Bureau of Statistics, 2011-2012), and this can lead to decreases in physical parameters such as strength, balance and endurance, which may lead to decline in the ability to maintain independence in activities of daily living and also to maintain living independently without assistance. Being physically active usually requires the older person to leave their home to perhaps go for a walk, meet friends at an exercise class or go to the park with their grandchildren and play games. The social interaction associated with physical activity conducted in groups or with others is also important for older people, as it can provide purpose and avoid social isolation, which may lead to mental health issues (Pate, 2014).

Many governments around the world have produced Physical Activity Guidelines for children, adults and older adults. For older adults, the World Health Organisation recommends at least 150 minutes of moderate-intensity aerobic activity or 75 minutes of vigorous aerobic activity a week, as well as three sessions of balance activities and two or more of muscle strength activities a week (World Health Organisation, 2011). Yet, few older people are meeting these minimum targets. A recent Australian national-representative sample study found only $5.5 \%$ of those aged 50 and over were meeting the recommended levels (Australian Government Department of Health, 2016) of muscle-strengthening activities per week (Bennie et al., 2016). Similar results have also been reported in Germany (Mayer et al., 2011), the United Kingdom (Strain, Fitzsimons, Kelly, \& Mutrie, 2016) and the United States of America (USA) (National Center for Health Statistics, 2015). Due to these low participation rates, studies have been published identifying possible motivators and barriers to encourage older people to meet the recommended guidelines, both for general physical activity (Baert, Gorus, Mets, Geerts, \& Bautmans, 2011) and resistance training specifically (Burton et al., 2016). 
Some of the main barriers to being physically active reported by older people are pain, injury or illness (Baert et al., 2011; Burton et al., 2016), but older people also report social barriers (Hill et al., 2011). These include having no one to exercise with, being unsure what to do, not knowing anyone doing any exercise, wanting to feel safe when exercising and the cost is also often prohibitive (Baert et al., 2011; Burton et al., 2016; Hill et al., 2011). The majority of physical activity, fitness or exercise programs are run by health professionals or those with formal qualifications. These people are mostly young and many target their programs towards younger or middle aged adults with few older adults being catered for specifically. The cost of these sessions, whether individual or group, also makes it difficult for some retired people to justify the expense even if they know they will benefit from participating (Bopp, Wilcox, Oberrecht, Kammermann, \& McElmurray, 2004; Keogh, Rice, Taylor, \& Kilding, 2014). It may be a mix of many factors, such as a lack of older health professionals conducting classes, fitness or activity facilities catering for younger people (e.g. loud music) and the cost that deters older people from attending. Hence, research interventions have started exploring the effectiveness of training peers to promote physical activity and assist in increasing the number of older adults being active.

Peer led programs are those delivered by peers after receiving training, and peer support programs include peers providing motivation, empathy and understanding to the participant rather than delivering the program. It has been suggested that three elements define a peer (Doull, O'Connor, Welch, Tugwell, \& Wells, 2005; Simoni, Franks, Lehavot, \& Yard, 2011). Firstly, peers have similar characteristics in common with the target group such as age, even though other characteristics may differ - for example gender, cultures, education or religion (Simoni et al., 2011). Additional aspects that may differentiate successful from non-successful peer programs include the peers being valued by management or the host organisation and that the peer led role is an integral part of the program/intervention being tested. Peers are also generally trained to deliver specific interventions rather than go outside the parameters, such as individualising exercise programs for clients. This is due to their often limited formal education within the area, such 
as health or exercise (Simoni et al., 2011). Peers often have an enhanced capacity to share, relate and empathise with their target group in a way that non-peers are often not able to (Doull et al., 2005).

Using peers may provide an opportunity for older people to be trained in delivering a program which builds their knowledge and skills possibly in a new area, for example in engaging in falls prevention (Khong, Bulsara, Hill, \& Hill, 2016) or delivering exercise programs. To the authors' knowledge no systematic reviews identifying the effectiveness of using peers to encourage older people to be more physically active have been published. Therefore, the aim of this systematic review was to determine the effectiveness of peer led or peer support programs aimed at encouraging older people to be physically active and improve physical outcomes.

\section{Methods}

\section{Eligibility criteria}

Studies meeting the following criteria were included in the review:

- Population: older adults (over 60 years, minimum 50\% sample population to ensure the interventions are aimed at older people)

- Intervention: peers to deliver programs (peer led) or motivate older people (peer support) to increase their participation in physical activity/exercise. Peer defined as older person, non-specialist, they must receive peer training as part of the intervention

- Outcomes: adherence to exercise program and/or measures of physical function

- Setting: community dwelling only

- Methodological approaches: quantitative research, uncontrolled evaluations and qualitative research.

Information sources and search strategy 
Data were sourced from six databases: Medline, CINAHL, PubMed, PsycInfo, SportDiscuss and Scopus from January 1976 to June 2016. Given we could find no previous systematic reviews exploring the use of peers to encourage older people to be physically active, the time period of 40 years was chosen because it was deemed to be extensive without including time periods where organised sport and recreation facilities (gymnasiums) were not readily accessed. Only articles published in English were included. No unpublished data, books, conference papers or posters or theses were included. Reference lists from the included studies were searched for additional studies. Keywords in the title and/or abstract were used to search and Table 1 outlines the search strategy undertaken in Medline. In some cases the language and syntax may have varied to accommodate the database. For example title and abstract were searched simultaneously in PubMed.

\section{Study selection}

Study selection took three stages; stage 1 involved one author (KF) scanning titles and excluding those not meeting inclusion criteria, during stage $2 \mathrm{KF}$ screened all abstracts again excluding studies that did not meet the inclusion criteria, and stage 3 involved two authors (KF and $\mathrm{EB}$ ) reading full articles to confirm final papers that met all criteria. Where disagreement occurred between the two authors discussions were held and a consensus reached by referring back to the inclusion criteria. To ensure methodology and results were collected and reported systematically, the PRISMA statement for reporting systematic reviews and meta-analyses was used (Liberati et al., 2009).

\section{Data collection process}

Data were extracted from the included studies for each of the following variables: design, aims, country, intervention, participant characteristics (sample size, age, sex), measures used, results (outcomes), exercise adherence. Information about the peer mentoring, including training and tasks, were also recorded where available. Data extraction forms were created by $\mathrm{EB}$ and the data were extracted independently by KF, with EB conducting data checks 
prior to study quality being determined, in accordance with the PRISMA-P guidelines (Shamseer et al., 2015). Authors of the original papers were not contacted for additional or missing data due to time constraints.

\section{Study quality}

The Cochrane Collaborative tool (Higgins et al., 2011) for assessing "risk of bias" was used by two authors (EB, KF) independently to determine study quality of all RCTs. The tool assesses seven different areas of potential bias including sequence generation, allocation concealment, participant and staff blinding, outcome assessor blinding, incomplete outcome data, selective outcome reporting and other sources of bias (Higgins et al., 2011). Risk of bias was assessed as low, medium or high (Higgins et al., 2011).

Quantitative studies that were not randomised trials, and qualitative studies were assessed for quality by two authors (EB, KF) individually using the Standard Quality Assessment Criteria for Evaluating Primary Research Papers from a variety of Fields (Kmet, Lee, \& Cook, 2004). This pragmatic tool uses 14 criteria to determine the quality of quantitative studies and 10 criteria for qualitative studies. Assessment options for each question included "yes", "no" and "not applicable". Summary scores for each study were calculated using the sum of ratings divided by the maximum scores of applicable data (Kmet et al., 2004). A third assessor, outside the study authors (Eileen Boyle) was also used where consensus was not reached.

\section{Data analysis}

Data from the articles included in the meta-analysis (i.e. means, standard deviations, standard error) were extracted from the original articles by EB and checked by KF. Where two or more studies collected similar outcome data a meta-analysis was conducted. Where papers did not report post-intervention data such as means or standard deviations they were not included in the meta-analyses. The mean difference (MD) and $95 \%$ confidence interval (95\%CI) were calculated for continuous outcomes. The Review Manager (RevMan) version 
5.2 was used to analyse the data and generate forest plots. $I^{2}$ and visual examination of funnel plots were used to assess heterogeneity as these are the recommended methods suggested for assessing heterogeneity in the Cochrane Handbook and Higgins and colleagues (2003) have reported previously that Cochrane's Q test may be poor in detecting true heterogeneity. The continuous outcomes were subjected to meta-analysis using the randomeffects inverse variance DerSimonian and Laird method (DerSimonian \& Laird, 1986). A random-effects model was used because it could not be assumed that each study was estimating the exact same quantity (Higgins \& Green, 2011). A p-value of less than 0.05 was considered statistically significant.

\section{Results}

\section{Study selection}

Figure 1 presents the study selection process. At the conclusion of all of the database searches 20,093 citations were generated. After removing duplicates from each individual database, 8,600 remained. Studies were screened against the inclusion criteria initially by title, then abstract and finally by full-text. Eighteen papers were judged to have met the inclusion criteria.

Insert Figure 1 here

Of the 18 papers accepted, 11 came from the USA, two from the United Kingdom and one from Australia, New Zealand, Malaysia, China and Canada. The included studies used a range of methodologies: six RCTs (Buman et al., 2011; Dorgo, King, Bader, \& Limon, 2011; Dorgo, King, \& Brickey, 2009; Iliffe et al., 2014; Sazlina, Browning, \& Yasin, 2015; Wong et al., 2014), four quasi-experimental studies (Barker et al., 2016; Dorgo, King, Bader, \& Limon, 2013; Waters, Hale, Robertson, Hale, \& Herbison, 2011), three pre- and post-test evaluations (Hickey et al., 1996; Hickey, Wolf, Robins, Wagner, \& Harik, 1995; Modra \& Black, 1999; Werner, Teufel, \& Brown, 2014), two longitudinal (Clark et al., 2012; Dorgo, 
Robinson, \& Bader, 2009), two descriptive evaluations (Grove \& Spier, 1999; Hammerback, Felias-Christensen, \& Phelan, 2012), and one 2 x 2 factorial study (Thomas et al., 2012).

\section{Study participants}

The 18 studies reviewed included 3,492 older people who participated in an intervention, sample sizes ranged from 14 to 1,256 participants. The average age of intervention participants was 66.5 years and $67.1 \%$ were female. Eight studies reported the number of peers involved and these ranged from one through to 36 ; average age 68.8 years, $46 \%$ were female. Table 2 presents the peer led study characteristics including aim, demographics, measures used, outcomes and findings, and Table 3 reports the peer support study characteristics.

Thirteen studies utilised peer led interventions which meant the peers were delivering the exercise classes to the participants (Barker et al., 2016; Buman et al., 2011; Dorgo et al., 2011, 2013; Dorgo, King, et al., 2009; Dorgo, Robinson, et al., 2009; Hammerback et al., 2012; Modra \& Black, 1999; Waters et al., 2011; Werner et al., 2014), although three of those started with nurses leading the exercises and after six weeks the peer leaders took over (Grove \& Spier, 1999; Hickey et al., 1996; Hickey et al., 1995). Peer support involved health professionals conducting the intervention and peers providing support alongside the health professional. Five studies included peer support which was usually over the phone or face-to-face and involved providing advice and encouragement (Clark et al., 2012; Iliffe et al., 2014; Sazlina et al., 2015; Thomas et al., 2012; Wong et al., 2014).

Insert Tables 2 and 3 here

\section{Intervention}

The interventions differed greatly across the 18 studies. Tables 2 and 3 present a brief description of each intervention and the length and dosage of each (if reported). Study 
periods ranged between 12-52 weeks, with an average of 21 weeks overall. Fifteen of the studies offered exercise interventions, which were predominantly a mix of aerobic and resistance training exercises, however one program included aquatic classes. Three other interventions offered advice and support which included the promotion of physical activity without offering a specific exercise intervention. Exercise dosage ranged from 30-75 minute sessions and from 1-5 times per week.

Twelve of the 18 included studies in this review described the method of training provided to peers, with the other third providing no details (Barker et al., 2016; Grove \& Spier, 1999; Hammerback et al., 2012; Hickey et al., 1995; Thomas et al., 2012). For those that did describe peer training, it ranged from describing how to complete exercises correctly and conducting a warm-up and cool-down during the walking test of the baseline assessment (Modra \& Black, 1999) to 30-weeks of peer training (Dorgo et al., 2011, 2013; Dorgo, King, et al., 2009; Dorgo, Robinson, et al., 2009). The 30-week peer training included peers attending three physical activity sessions per week to improve their fitness levels. The first 14 weeks also included sessions on exercise and training techniques for older people (e.g. cardiovascular fitness, muscle strength) and weeks 15-30 included an additional emphasis on peer-mentoring which involved participating in educational sessions on ageing, health, fitness and mentoring (Dorgo et al., 2011, 2013; Dorgo, King, et al., 2009; Dorgo, Robinson, et al., 2009). Most of the other peer training sessions included instruction on delivering exercises, how to be a mentor, safety aspects of delivering exercise programs, and methods of communication. Six studies used role-play during their peer training (Dorgo et al., 2011, 2013; Dorgo, King, et al., 2009; Dorgo, Robinson, et al., 2009; Werner et al., 2014; Wong et al., 2014) and Hickey and colleagues $(1996 ; 1995)$ individualised their training to suit the peers (no further information provided).

\section{Adherence and withdrawal rates}


Barker and colleagues (2016) aquatic study reported $65 \%$ of intervention participants completed 6 or more classes, of a total 12 available. Over half of the participants (57\%) in Grove et al.'s study attended at least 26 sessions over the six month intervention period and two of the three groups were still continuing to participate after two years for Hickey et al.'s (1996) study. The peer educators completed $75 \%$ of the planned phone calls compared to $87 \%$ by the respiratory therapists in Wong et al.'s (2014) study to assist patients with Chronic Obstructive Pulmonary Disease (COPD). Adherence to the intervention was not described in the other studies. There was little difference between the intervention and control groups for withdrawal rates for all of the included studies (intervention: 22.6\%, control: 20.6\%) with over three quarters of both groups completing post-outcome assessments. When comparing peer led studies with control groups the participation rates were $76.8 \%$ and $80.7 \%$ respectively, whereas the participations rates for the peer support were $79.2 \%$ for the intervention participants and $79.3 \%$ for the control groups.

\section{Study outcomes}

Two studies (Hammerback et al., 2012; Wong et al., 2014) did not consider their interventions to be successful enough to recommend translation into practice. Hammerback and colleagues suggested they had to spend too much time and money recruiting both peers and participants for the intervention to be considered viable, and Wong et al (2014) concluded peer support over the phone was no more successful than usual care in improving health outcomes for people living with COPD. The other 16 studies all reported improvements in either levels of physical activity or physical function. Buman and colleagues suggested trained peers may enhance long-term maintenance, and similarly, another study appeared sustainable because their intervention was continuing three years after the study was completed (Hickey et al., 1996).

Six studies (Dorgo et al., 2011, 2013; Dorgo, King, et al., 2009; Dorgo, Robinson, et al., 2009; Hickey et al., 1996; Modra \& Black, 1999) suggested their peer led interventions may be as effective as those run by health professionals, and as such, may also be cost- 
effective. However, only one study commented on the cost of the intervention (FAME: Falls Management Exercise program) compared to the peer led or usual care programs, and they found the peer led intervention to be cost effective compared to the main intervention: FAME (Iliffe et al., 2014).

\section{Quality of studies}

Table 4 (on-line supplementary only) presents the potential bias of the six RCTs, Thomas et al.'s (2012) 2 x 2 factorial study and Dorgo, Robinson, et al. (2009) two arm longitudinal study, using the risk of bias tool. Sazlina et al. (2015) was the only RCT deemed to have low risk of bias for each question, and Iliffe and colleagues (2014) had low risk except for blinding (participants and outcome assessors) where it was deemed to be unclear. No study had high risk of bias, however all other RCTs had at least one area of unclear risk of bias, most notably sequence generation, allocation concealment and blinding, due to lack of information within the paper. Overall, most of the RCTs were rated as medium quality studies.

The Standard Quality Assessment Criteria for Evaluating Primary Research Papers was utilised for the additional 10 included studies and the quality scores are presented in Table 5 (on-line supplementary only). Scores ranged from 55-100\% quality, with an average of $80.5 \%$ across the 10 studies. Overall the quality of the studies was medium to high.

\section{Meta-analysis}

There were only two measures that were reported in two or more studies with available data suitable for meta-analyses. The 6 minute walk test (6MWT) was utilised by Dorgo et al., (2011), Dorgo, King, et al. (2009) and Wong et al. (2014) and the Timed Up and Go (TUG) by Dorgo et al. (2011), Dorgo, King, et al. (2009) and Iliffe, et al (2014). The peer led and peer supported interventions were analysed within the same meta-analyses because both were aimed at improving health and physical activity outcomes and included physical activity interventions that were either delivered face to face or via motivating over the phone. 
Figure 2 reports the forest plots for the 6MWT. No overall heterogeneity was found between the three studies $\left(I^{2}=0 \%\right)$. On completion of the intervention period the control group walked significantly further for 6MWT than the intervention group $(\mathrm{MD}[95 \% \mathrm{CI}]=-22.10[-32.34$ to -11.86$], \mathrm{p}<0.0001)$. The overall heterogeneity between the three studies for the TUG was low $\left(I^{2}=8 \%\right)$ as shown in the forest plot in Figure 3. Similar to the 6MWT, the TUG improved more in the control group than the intervention group $(\mathrm{MD}[95 \% \mathrm{CI}]=0.30[0.01$ to 0.59 ], $\mathrm{p}=0.04$ ). It should be noted that for both meta-analyses the sample sizes were small, except for the Iliffe et al. (2014) study, and therefore should be interpreted with caution.

Insert Figure 2 here

Insert Figure 3 here

\section{Discussion}

Much research has explored interventions that promote older adults becoming more physically active, yet the prevalence of older people meeting physical activity guidelines remains low (Brownie, 2005; Keadle, McKinnon, Graubard, \& Troiano, 2016). This systematic review has found that in the late 1990s there was some interest in using peers to deliver or support the uptake of physical activity by older people (Grove \& Spier, 1999; Hickey et al., 1996; Hickey et al., 1995; Modra \& Black, 1999) and again more recently (Barker et al., 2016; Buman et al., 2011; Clark et al., 2012; Dorgo et al., 2011, 2013; Dorgo, King, et al., 2009; Dorgo, Robinson, et al., 2009; Hammerback et al., 2012; Iliffe et al., 2014; Sazlina et al., 2015; Thomas et al., 2012; Waters et al., 2011; Werner et al., 2014; Wong et al., 2014).

The papers included in this systematic review have reported that peer led or peer supported programs may be as effective in maintaining participation of older adults in exercise programs as those using health professionals. However, the meta-analyses data did 
not confirm these findings. It must be noted however that the meta-analyses did not include many studies or variables as there was a broad range of measurement outcomes used and therefore should be used with caution. Two studies did not deem the intervention to be appropriate for translating into practice (Hammerback et al., 2012; Wong et al., 2014), firstly because the authors proposed recruitment of both the peers and participants was too difficult (targeting disadvantaged older people) and Wong et al. (2014) concluded using peer support over the phone was not as successful as face-to-face or a combination of both.

Adverse events were rarely reported and the retention rates using peers were consistently above $75 \%$ for most studies, with some reporting retention rates of $90 \%$ and above, demonstrating peer led programs can be as successful in retaining participants as those led by health professionals. When comparing to studies aimed at increasing physical activity participation for older people not including a peer, the adherence rates in the included studies are as high or higher (>75\%) than other studies reported (42.6- 86\%) (Garmendia et al., 2013; Picorelli, Pereira, Pereira, Felıcio, \& Sherrington, 2014). Picorelli and colleagues in their systematic review reported adherence rates for older people to be higher when physical activity programs were supervised and using peers may be an affordable option for maintaining activity programs that are 'supervised,' because cost is often reported as a barrier to older people participating in activity programs (Bopp et al., 2004; Keogh et al., 2014).

The peers in the Modra and Black (1999) study started a walking group which included walking 4-5 times a week for approximately 30-60 minutes, which was in addition to the actual intervention. This showed initiative that may not normally occur during intervention studies not including peers, and provides evidence that being social during physical activity sessions is important to older people. These findings are supported by a number of studies that have found older people like the social aspects when participating in physical activity, often being one of the main reasons along with improving health status as to why they participate (Baert et al., 2011; Burton et al., 2016). 
Interventions that used education (i.e. advice and support) to promote an increase in physical activity, without being linked to an exercise program were also trialled to improve adherence and physical outcomes for older people. It is unclear whether these interventions are more effective than those directly delivering exercise interventions to improve physical function and more research is required to determine their effectiveness. Nevertheless, they were successful for continuing adherence to the intervention. Also of note was that the Sazlina et al., (2015) and Wong et al., (2014) studies both recruited peers who had previously completed the program (intervention) and were only needing to be trained to provide peer support and would work alongside health professionals. It might be expected that these peers could empathise with the participants and provide strong support to the health professionals to include additional benefit, which may be a reason contributing to the intervention groups adhering to the exercise program as much (or more) than the controls to usual care. Other studies have used peer support and also found having peers who relate to the topic due to similar experiences and work as a positive role model were beneficial (Allen, 2004; Gakumo, Enah, Vance, Sahinoglu, \& Raper, 2015). For example, Sadler and colleagues found stroke survivors working as peers to improve resilience for others who had also experienced a stroke were effective (Sadler, Sarre, Tinker, Bhalla, \& McKevitt, 2016).

\section{Strengths and limitations}

The rigorous approach utilised to conduct the systematic review was a strength of the study. This included using two different tools to determine the quality of the articles included in the review. Overall the methodological quality of studies was medium to high. A limitation of the review approach was that only one author (KF) conducted the initial search of titles and abstracts and extracted the original data which was then checked against each included publication by EB, therefore there may be a risk of selection bias. A limitation of the studies included in the review was that almost $90 \%$ of the participants were from predominantly English speaking countries, with almost two-thirds coming from the USA. Only two studies were from Asia (Malaysia and China) and none from mainland Europe, Africa or South 
America. Therefore, the generalisability of using peers to promote physical activity may not be as applicable in these different environments and cultural settings that are currently missing in the literature. Publication bias was not able to be calculated due to fewer than 10 RCT studies in the meta-analyses being available (Higgins \& Green, 2011). Language bias may have also occurred because only studies published in English were included. Although the search was extensive in time period (1976-2016) and across six databases there is always the chance that a paper may not have been included, however every effort was made to include all articles meeting the inclusion criteria. It must also be noted that the study search was completed in June 2016, therefore there may be additional studies published since then. Grey literature was also not searched which may have broadened the number of studies included. However, given challenges of accessing grey literature that are often not accessible electronically and possible inconsistencies in quality it was determined to restrict the search to peer-reviewed publications. The 18 studies included in the review presented results in various ways using different methodologies and measures, which made it difficult to conduct meaningful meta-analyses to determine effectiveness across the studies. Due to the peer-led and peer-supported interventions both being aimed at improving health and physical activity outcomes we felt these were appropriate to combine into the one meta-analysis to provide some data on the effectiveness of peers to encourage physical activity for older people. However, caution must be taken when interpreting the results. There is a definite need for further adequately powered studies using similar measures to strengthen the interpretation of the results of this review, including cost-effectiveness studies.

\section{Conclusion}

This systematic review is the first to look at the effectiveness of using peers to promote physical activity and improve physical outcomes for older people. Older people who are physically active can promote and deliver physical activity interventions safely and achieve high adherence to the program over the long term. There is also some evidence that their involvement may be as effective as health professionals. However, it remains unclear 
whether peers have a positive effect on improving physical outcomes particularly for disadvantaged older people and those receiving support not directly linked to the exercise intervention. It is recommended that future research involve larger samples and use similar measurement tools to the studies included in this review. This would create a better understanding of the evidence and allow policy makers to make informed decisions on endorsing peer involvement in the promotion of physical activity. 


\section{References}

Allen, T. (2004). Preventing falls in older people: Evaluating a peer education approach. British Journal of Community Nursing, 9(5), 195-200

Australian Bureau of Statistics. (2011-2012).43640DO008_20112012 Australian health survey: Physical activity, 2011-12 - Australia. Table 10.3 Frequency and duration of physical activity, Proportion of persons aged 18 years and over. Retrieved from

http://www.abs.gov.au/AUSSTATS/abs@.nsf/DetailsPage/4364.0.55.004201

\section{$\underline{1-12 \text { ? OpenDocument }}$}

Australian Government Department of Health. (2016). Recommendations on physical activity for health for older Australians. Retrieved from

http://www.health.gov.au/internet/main/publishing.nsf/content/phd-physical$\underline{\text { rec-older-guidelines }}$

Baert, V., Gorus, E., Mets, T., Geerts, C., \& Bautmans, I. (2011). Motivators and barriers for physical activity in the oldest old: A systematic review. Ageing Research Reviews, 10, 464-474. doi: 10.1016/j.arr.2011.04.001

Barker, A. L., Talevski, J., Morello, R. T., Nolan, G. A., De Silva, R. D., \& Briggs, A. M. (2016). Jumping into the deep-end: results from a pilot impact evaluation of a community-based aquatic exercise program. Clinical rheumatology, 35(6), 1593-1601. doi: http://dx.doi.org/10.1007/s10067-015$\underline{3096-6}$

Bennie, J., Pedisic, Z., van Uffelen, J., Charity, M., Harvey, J., Banting, L., . . Eime, R. (2016). Pumping iron in Australia: Prevalence, trends and sociodemographic correlates of muscle strengthening activity participation 
from a national sample of 195,926 adults. PlOS One, 11(4), e0153225. doi: 10.1371/journal.pone.0153225

Bopp, M., Wilcox, S., Oberrecht, L., Kammermann, S., \& McElmurray, C. (2004). Correlates of strength training in older rural African American and Caucasian women. Women and Health, 40(1), 1-20. doi: 10.1300/J013v40n01_01

Brownie, S. (2005). The physical activity patterns of older Australians. Australian Journal of Primary Health, 11(3), 79-87

Buman, M. P., Giacobbi, J. P. R., Dzierzewski, J. M., Morgan, A. A., McCrae, C. S., Roberts, B. L., \& Marsiske, M. (2011). Peer Volunteers Improve Long-Term Maintenance of Physical Activity With Older Adults: A Randomized Controlled Trial. Journal of Physical Activity \& Health, 8, S257-S266

Burton, E., Farrier, K., Lewin, G., Pettigrew, S., Hill, A.-M., Airey, P., . . Hill, K. (2016). Motivators and barriers for older people participating in resistance training: A systematic review. Journal of Aging and Physical Activity, accepted 25 July 2016

Clark, A. M., Munday, C., McLaughlin, D., Catto, S., McLaren, A., \& Macintyre, P. D. (2012). Peer support to promote physical activity after completion of centre-based cardiac rehabilitation: evaluation of access and effects. European journal of cardiovascular nursing : journal of the Working Group on Cardiovascular Nursing of the European Society of Cardiology, 11(4), 388-395. doi: http://dx.doi.org/10.1016/j.ejcnurse.2010.12.001

DerSimonian, R., \& Laird, N. (1986). Meta-analysis in clinical trials. Controlled Clinical Trials, 7(3), 177-188

Dorgo, S., King, G. A., Bader, J. O., \& Limon, J. S. (2011). Comparing the effectiveness of peer mentoring and student mentoring in a 35-week fitness 
program for older adults. Archives of gerontology and geriatrics, 52(3), 344349. doi: http://dx.doi.org/10.1016/j.archger.2010.04.007

Dorgo, S., King, G. A., Bader, J. O., \& Limon, J. S. (2013). Outcomes of a peer mentor implemented fitness program in older adults: A quasi-randomized controlled trial. International Journal of Nursing Studies, 50(9), 1156-1165 1110p. doi: 10.1016/j.ijnurstu.2012.12.006

Dorgo, S., King, G. A., \& Brickey, G. D. (2009). The application of peer mentoring to improve fitness in older adults. Journal of Aging \& Physical Activity, 17(3), 344-361 318p

Dorgo, S., Robinson, K. M., \& Bader, J. (2009). The effectiveness of a peermentored older adult fitness program on perceived physical, mental, and social function. Journal of the American Academy of Nurse Practitioners, 21(2), 116-122 117p. doi: 10.1111/j.1745-7599.2008.00393.x

Doull, M., O'Connor, A., Welch, V., Tugwell, P., \& Wells, G. (2005). Peer support strategies for improving the health and well-being of individuals with chronic diseases. Cochrane Database of Systematic Reviews, Issue 3. Art. No.: CD005352. doi: 10.1002/14651858.CD005352

Gakumo, C., Enah, C., Vance, D., Sahinoglu, E., \& Raper, J. (2015). “Keep it simple": older African Americans' preferences for a health literacy intervention in HIV management. Patient Preferences and Adherence, 9, 217-223. doi: https://doi.org/10.2147/PPA.S69763

Garmendia, M., Dangour, A., Albala, C., Eguiguren, P., Allen, E., \& Uauy, R. (2013). Adeherence to a physical activity intervention among older adults in a post-transitional middle income country: A quantitative and qualitative analysis. The Journal of Nutrition, Health \& Aging, 17(5), 466-471 
Grove, N., \& Spier, B. (1999). Motivating the well elderly to exercise. Journal of Community Health Nursing, 16(3), 179-189

Hammerback, K., Felias-Christensen, G., \& Phelan, E. A. (2012). Evaluation of a telephone-based physical activity promotion program for disadvantaged older adults. Preventing Chronic Disease, 9, E62-E62 61p

Hickey, T., Sharpe, P. A., Wolf, F. M., Robins, L. S., Wagner, M. B., \& Harik, W. (1996). Exercise participation in a frail elderly population. Journal of health care for the poor and underserved, 7(3), 219-231

Hickey, T., Wolf, F. M., Robins, L. S., Wagner, M. B., \& Harik, W. (1995). Physical activity training for functional mobility in older persons. Journal of Applied Gerontology, 14(4), 357-371. doi:

http://dx.doi.org/10.1177/073346489501400401

Higgins, J., Altman, D., Gøtzsche, P., Jüni, P., Moher, D., Oxman, A., . . Cochrane Statistical Methods Group. (2011). The Cochrane Collaboration's tool for assessing risk of bias in randomised trials. British Medical Journal, 343, d5928. doi: 10.1136/bmj.d5928

Higgins, J., \& Green, S. (2011). Cochrane Handbook for Systematic Reviews of Interventions Version 5.1.0 [updated March 2011] Retrieved from www.cochrane-handbook.org

Higgins, J., Thompson, S., Deeks, J., \& Altman, D. (2003). Measuring inconsistency in meta-analyses. British Medical Journal, 327, 557-560

Hill, A.-M., Hoffmann, T., McPhail, S., Beer, C., Hill, K., Brauer, S., \& Haines, T. (2011). Factors associated with older patients' engagement in exercise after hospital discharge. Archives of Physical Medicine and Rehabiliation, 92(9), 1395-1403. doi: 10.1016/j.apmr.2011.04.009 
Iliffe, S., Kendrick, D., Morris, R., Masud, T., Gage, H., Skelton, D., . . B Belcher, C. (2014). Multicentre cluster randomised trial comparing a community group exercise programme and home-based exercise with usual care for people aged 65 years and over in primary care. Health Technology Assessment, 18(8), 1106 106p. doi: 10.3310/hta18490

Keadle, S., McKinnon, R., Graubard, B., \& Troiano, R. (2016). Prevalence and trends in physical activity among older adults in the United States: A comparison across three national surveys. Preventive Medicine, 89, 37-43. doi: http://dx.doi.org/10.1016/j.ypmed.2016.05.009

Keogh, J., Rice, J., Taylor, D., \& Kilding, A. (2014). Objective benefits, participant perceptions and retention rates of a New Zealand community-based, olderadult exercise programme. Journal of Primary Health Care, 6(2), 114-122

Khong, L., Bulsara, C., Hill, K., \& Hill, A.-M. (2016). How older adults would like falls prevention information delivered: Fresh insights from a World Café forum. Ageing \& Society. doi: https://doi.org/10.1017/S0144686X16000192

Kmet, L., Lee, R., \& Cook, L. (2004). Standard Quality Assessment Criteria for Evaluating Primary Research papers from a Variety of Fields. Alberta.

Liberati, A., Altman, D., Tetzlaff, J., Mulrow, C., Gotzsche, P., Ioannidis, J., . . . Moher, D. (2009). The PRISMA statement for reporting systematic reviews and meta-analyses of studies that evaluate health care interventions: Explanation and elaboration. BMJ, 339(b2700). doi: http://dx.doi.org/10.1136/bmj.b2700

Mayer, F., Scharhag-Rosenberger, F., Carlsohn, A., Cassel, M., Müller, S., \& Scharhag, J. (2011). The intensity and effects of strength training in the 
elderly. Deutsches Ärzteblatt International, 108(21), 359-364. doi:

10.3238/arztebl.2011.0359

Modra, A. K., \& Black, D. R. (1999). Peer-led minimal intervention: an exercise approach for elderly women. American Journal of Health Behavior, 23(1), $52-6059 \mathrm{p}$

National Center for Health Statistics. (2015). Health, United States, 2014: With special feature on adults aged 55-64. Hyattsville, MDhttp://www.cdc.gov/nchs/data/hus/hus14.pdf.

Pate, A. (2014). Social Isolation: Its impact on the mental health and wellbeing of older Victorians. Melbourne, VIC.http://cotavic.org.au/wpcontent/uploads/2014/02/Working-Paper_Social-Isolation.pdf.

Picorelli, A., Pereira, L., Pereira, D., Felıcio, D., \& Sherrington, C. (2014). Adherence to exercise programs for older people is influenced by program characteristics and personal factors: a systematic review. Journal of Physiotherapy, 60, 151-156. doi:

http://dx.doi.org/10.1016/j.jphys.2014.06.012

Sadler, E., Sarre, S., Tinker, A., Bhalla, A., \& McKevitt, C. (2016). Developing a novel peer support intervention to promote resilience after stroke. Health and Social Care in the Community. doi: 10.1111/hsc.12336

Sazlina, S. G., Browning, C. J., \& Yasin, S. (2015). Effectiveness of Personalized Feedback Alone or Combined with Peer Support to Improve Physical Activity in Sedentary Older Malays with Type 2 Diabetes: A Randomized Controlled Trial. Front Public Health, 3, 178. doi: 10.3389/fpubh.2015.00178

Shamseer, L., Moher, D., Clarke, M., HGhersi, D., Liberati, A. d., Petticrew, M., . . . PRISMA-P Group. (2015). Preferred reporting items for systematic review 
and meta-analysis protocols (PRISMA-P) 2015: elaboration and explanation. BMJ, 349, g7647. doi: 10.1136/bmj.g7647

Simoni, J., Franks, J., Lehavot, K., \& Yard, S. (2011). Peer interventions to promote health: Conceptual considerations. American Journal of Orthopsychiatry, 81(3), 351-359. doi: 10.1111/j.1939-0025.2011.01103.x

Strain, T., Fitzsimons, C., Kelly, P., \& Mutrie, N. (2016). The forgotten guidelines: cross-sectional analysis of participation in muscle strengthening and balance \& co-ordination activities by adults and older adults in Scotland. BMC Public Health, 16(1108). doi: 10.1186/s12889-016-3774-6

Thomas, N. G., MacFarlane, D. J., Guo, B., Cheung, B. M. Y., McGhee, S. M., Chou, K. L., . . Tomlinson, B. (2012). Health promotion in older chinese: A 12-month cluster randomized controlled trial of pedometry and peer support. Medicine and Science in Sports and Exercise, 44(6), 1157-1166. doi: 10.1249/MSS.0b013e318244314a

Warburton, D., Nicol, C., \& Bredin, S. (2006). Health benefits of physical activity: The evidence. Canadian Medical Association Journal, 174(6), 801-809. doi: 10.1503/cmaj.051351

Waters, D. L., Hale, L. A., Robertson, L., Hale, B. A., \& Herbison, P. (2011). Evaluation of a Peer-Led Falls Prevention Program for Older Adults. Archives of Physical Medicine \& Rehabilitation, 92(10), 1581-1586 1586p. doi: 10.1016/j.apmr.2011.05.014

Werner, D., Teufel, J., \& Brown, S. L. (2014). Evaluation of a Peer-Led, LowIntensity Physical Activity Program for Older Adults. American Journal of Health Education, 45(3), 133-141 139p. doi: 10.1080/19325037.2014.893851 
Wong, E. Y., Jennings, C. A., Rodgers, W. M., Selzler, A. M., Simmonds, L. G., Hamir, R., \& Stickland, M. K. (2014). Peer educator vs. respiratory therapist support: Which form of support better maintains health and functional outcomes following pulmonary rehabilitation? Patient Education and Counseling, 95(1), 118-125. doi: 10.1016/j.pec.2013.12.008

World Health Organisation. (2011). Global recommendations on physical activity for health 65 years and above. Retrieved from http://www.who.int/dietphysicalactivity/physical-activity-recommendations65years.pdf 
Table 1 Search strategy (according to Medline (ProQuest) terminology)

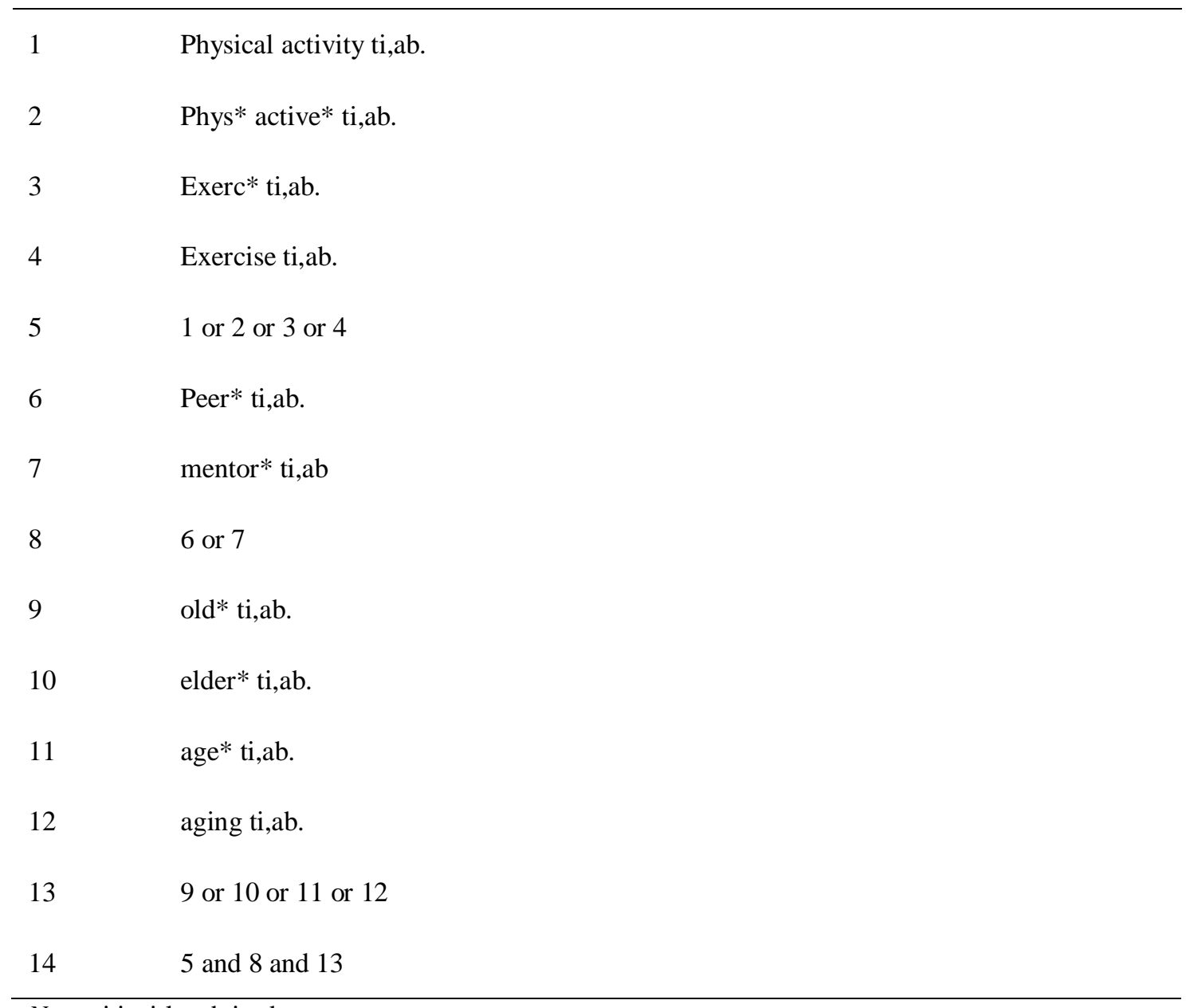

Note. ti is title, ab is abstract 
Table 2 Peer-led studies and participant characteristics

\begin{tabular}{|c|c|c|c|c|}
\hline $\begin{array}{l}\text { Reference, country, } \\
\text { study design and } \\
\text { setting }\end{array}$ & Study question/aims & $\begin{array}{l}\text { Participants (sample size, } \\
\text { female }(\mathrm{N}) \text {, mean age (age } \\
\text { range) }\end{array}$ & Intervention and measures & Follow-up and outcomes \\
\hline $\begin{array}{l}\text { Barker et al. (2016) } \\
\text { Australia } \\
\text { Multi-center quasi- } \\
\text { experimental pilot } \\
\text { study } \\
\text { Community swimming } \\
\text { pool }\end{array}$ & $\begin{array}{l}\text { Evaluate changes in pain, } \\
\text { joint stiffness, physical } \\
\text { function, and quality of life } \\
\text { over } 12 \text { weeks in adults } \\
\text { with musculoskeletal } \\
\text { conditions attending } \\
\text { 'Waves' aquatic exercise } \\
\text { classes. }\end{array}$ & $\begin{array}{l}\text { 109; } 89 \text { female; } 65.2 \text { years; } \\
\text { musculoskeletal conditions } \\
\text { Intervention: } 67,57 \text { female; } \\
68.5(13.1) \text { years } \\
\text { Control (no exercise): } 42 ; 3 \\
\text { female; } 59.9 \text { (14.8) years }\end{array}$ & $\begin{array}{l}\text { Peer-led, } 45 \text { min, weekly aquatic exercise } \\
\text { class including aerobic, strength, flexibility, } \\
\text { and balance exercises. } \\
\text { Western Ontario and McMaster Universities } \\
\text { Osteoarthritis Index (WOMAC) EuroQoL } \\
\text { five dimensions survey (EQ-5D) (HRQoL) } \\
\text { Satisfaction with Waves classes. }\end{array}$ & $\begin{array}{l}12 \text { weeks: Over } 90 \% \text { reported } \\
\text { satisfaction with classes and would } \\
\text { recommend to others. } \\
\text { Improvements in WOMAC and } \\
\text { EQ-5D scores however between- } \\
\text { group differences did not reach } \\
\text { statistical significance. }\end{array}$ \\
\hline $\begin{array}{l}\text { Buman et al. (2011) } \\
\text { USA } \\
\text { RCT } \\
\text { Community exercise } \\
\text { facility }\end{array}$ & $\begin{array}{l}\text { Whether tailored support } \\
\text { from older peer volunteers } \\
\text { could improve initiation } \\
\text { and long-term maintenance } \\
\text { of physical activity } \\
\text { behaviour }\end{array}$ & $\begin{array}{l}\text { Peer volunteers: } 7 ; 67.3 \pm \\
4.2 \text { years } \\
\text { Total: } 81 ; 67 \text { female; } 63.42 \pm \\
8.62 \text { years } \\
\text { Peer group: } 41 ; 35 \text { female; } \\
63.5 \pm 8.3 \text { years } \\
\text { Standard: } 40 ; 32 \text { female } 63.4 \\
\pm 9.1 \text { years }\end{array}$ & $\begin{array}{l}\text { Group-based programs: (Group 1) peer led } \\
\text { advice and support for physical activity (PA) } \\
\text { initiation and maintenance; (Group 2) } \\
\text { standard community PA promotion } \\
\text { intervention. Given access to exercise } \\
\text { facility and pedometer for self-monitoring } \\
\text { MVPA assessed using daily self-report logs } \\
\text { (from The Leisure-Time Exercise } \\
\text { Questionnaire (LTEQ)) Random subsample } \\
\text { (22) wore RT3 accelerometer. } \\
\text { Cardiorespiratory fitness ( } \mathrm{VO}_{2} \text { peak), barriers } \\
\text { and exercise self efficacy and The Exercise } \\
\text { Motivation Scale. }\end{array}$ & $\begin{array}{l}16 \text { weeks: similar improvements in } \\
\text { MVPA and cardiorespiratory } \\
\text { fitness. } \\
18 \text { months: Peer group greater } \\
\text { MVPA, standard began to return } \\
\text { back to their baseline levels. } \\
\text { Retention: } 85 \% \text { @ } 16 \text { weeks, } 61 \% \\
@ 18 \text { months }\end{array}$ \\
\hline Dorgo et al. (2011) & $\begin{array}{l}\text { Compare the retention and } \\
\text { participation rates, and } \\
\text { physical improvements of } \\
\text { older adults trained by peer } \\
\text { mentors (PM) to a group } \\
\text { trained by young qualified }\end{array}$ & $\begin{array}{l}\text { Peer mentors: } 30 ; 15 \text { female; } \\
68.4 \pm 5.9 \text { years } \\
\text { Exercisers: } 60 ; 29 \text { female; } \\
68.7 \pm 6.1 \text { years } \\
\text { PM exercisers: } 30 ; 14\end{array}$ & $\begin{array}{l}\text { Peer mentors: } 30 \text {-week preparation program } \\
\text { to improve their physical fitness and } \\
\text { mentorship skills. } 2 \text { x week } 75 \text {-minute } \\
\text { training sessions aimed to improve balance, } \\
\text { flexibility, cardiovascular fitness and } \\
\text { muscular strength. }\end{array}$ & $\begin{array}{l}35 \text { weeks: both groups improved all } \\
\text { fitness measures pre to post } \\
\text { training. SM exercisers had slightly } \\
\text { higher participation rate. } \\
19 \text { from each group completed } 35 \\
\text { week program ( } 63 \% \text { retention rate). }\end{array}$ \\
\hline
\end{tabular}


student mentors (SM).

female; $67.8 \pm 4.5$ years

SM exercisers: $30 ; 15$

female; $69.3 \pm 6.3$ years

\begin{tabular}{ll}
\hline Dorgo et al. (2013) & $\begin{array}{l}\text { Compare physical fitness } \\
\text { scores, retention and } \\
\text { participation rates of older } \\
\text { adults trained by student } \\
\text { mentors (SM), peer } \\
\text { mentors (PM), peer } \\
\text { mentors working } \\
\text { Quasi-randomised } \\
\text { study }\end{array}$ \\
independently of the \\
University & $\begin{array}{l}\text { nosearchers (PMI), and a } \\
\text { group. }\end{array}$ \\
& $\begin{array}{l}\text { Compare the program } \\
\text { perception, retention and } \\
\text { participation rates, and } \\
\text { physical improvements of } \\
\text { older adults trained by peer } \\
\text { mentors (PM) with those } \\
\text { of a group trained by } \\
\text { student mentors (SM). }\end{array}$ \\
\hline Dorgo, King, et al. & \\
(2009) &
\end{tabular}

3.6 years

6.3 years

PM exercisers: $52 ; 35$

women; $68.1 \pm 5.7$ years

PMI exercisers: $12 ; 5$

female; $65.2 \pm 3.6$ years

16 female; $77.9 \pm 9.2$

5.9 years

PM exercisers $60 ; 29$

female; $68.7 \pm 6.1$ years 30-second chair stand, arm curl strength,

chair sit-and-reach, back scratch flexibility,

6-min walk test, forward reach, and 8-ft up-

and-go.

Participation and retention rates.

PM: 31; 11 female; $65.1 \pm$

PM: 30-week preparation program to

improve their physical fitness and

PMI: 5; 2 female; $64.1 \pm 2.0$ mentorship skills. Intervention: 14 weeks $2 \mathrm{x}$

SM: $24 ; 16$ female; $69.6 \pm$ week 75 -minute training sessions

30-second chair stand, 30-second arm curl

tests, hand grip dynamometry, chair sit-and-

reach and back scratch tests, 6-min walk

test, 8-ft up-and-go test, forward reach test.

Retention and participation rates.

Non exercising controls: 18 ;

PM: 30; 15 female; $68.4 \pm$

\section{PM: 30-week preparation program to}

improve their physical fitness and

mentorship skills. Intervention: 14 weeks $3 \mathrm{x}$

week 75-minute training sessions.

30-second chair stand, 30-second arm curl

tests, hand grip dynamometry, chair sit-and-

reach, back scratch tests, 6-min walk test, 8

$\mathrm{ft}$ up-and-go test, forward reach test.

Program Perception Survey: program enjoyment, perceived program benefits, and the effectiveness of mentors.

Dorgo, Robinson, et al. Compare changes in (2009) perceived physical, mental, and social function in a

USA group of older adults who were trained by peer

Two arm repeated mentors (PMs) versus a measures longitudinal
PM: $30 ; 15$ female; $68.6 \pm 5.8$ years

SM: 54; 31 female; $69.2 \pm 6.6$

years

PM exercisers: $95 ; 55$

female; $68.7 \pm 5.9$ years

Cohort 1- 60; 29 female;
: 30 -week preparation program to improve their physical fitness and week 75-minute training sessions to improve cardiovascular fitness, muscular strength, muscle mass, power, balance, and flexibility SF-36v2 all eight subscales and the two mentorship skills. Intervention: 14 weeks $3 x$
44 weeks total: All 3 mentored groups improved fitness measures and had high participation and retention rates (ranged from 84 $100 \%$ )

44 weeks total (30 weeks PM training): High retention in both groups (SM 76.7\%, PM 90\%).

SM group had higher participation (SM $82.3 \%$, PM 72\%).

Both groups improved fitness, no significant post-test differences

between the groups in most fitness measures (SM scored higher in 30second chair stand and 8-ft up-andgo). Similar scores for Program Perception Survey.

14 weeks: Retention: PM 91.6\%, SM $81.5 \%$ Both groups improved fitness measures. Perceived physical, mental, and social functioning improved significantly for the PM group, but not for the SM group (overall improvement in 


\begin{tabular}{|c|c|c|c|c|}
\hline intervention & $\begin{array}{l}\text { qualified kinesiology } \\
\text { student mentors (SMs). } \\
2 \text { different cohorts. }\end{array}$ & $\begin{array}{l}68.7 \pm 6.1 \text { years } \\
\text { Cohort } 2-89 ; 57 \text { female; } \\
69.4 \pm 6.2 \text { years }\end{array}$ & $\begin{array}{l}\text { summary physical and mental component } \\
\text { scores. }\end{array}$ & $\begin{array}{l}\text { physical and mental well-being, } \\
\text { better social functioning, enhanced } \\
\text { ability to carry out physical and } \\
\text { emotional roles, improved general } \\
\text { health, and increased level of } \\
\text { vitality). }\end{array}$ \\
\hline $\begin{array}{l}\text { Descriptive study } \\
\text { (evaluation) } \\
\text { Community room of } \\
\text { apartment block }\end{array}$ & $\begin{array}{l}\text { This article describes } \\
\text { intervention strategies and } \\
\text { evaluates their usefulness } \\
\text { in motivating adherence to } \\
\text { an exercise program } \\
\text { designed specifically for } \\
\text { well-elderly community } \\
\text { dwellers (living within } \\
\text { apartment block). }\end{array}$ & $14 ; 14$ female; 78 years & $\begin{array}{l}52 \text { sessions using So Much Improvement } \\
\text { with a Little Exercise (SMILE) videotape. } \\
\text { 1: Leadership by a Health Care Provider } \\
\text { (nurse): } 2 \mathrm{x} \text { week for } 6 \text { weeks then } 1 \mathrm{x} \text { week } \\
\text { for } 4.5 \text { months } \\
\text { 2: Peer Support: after } 6 \text { weeks peer captain } \\
\text { exercised } 2 \mathrm{x} \text { week with group ( } 3-4 \\
\text { members) without the nurse (move towards } \\
\text { exercising in independence) } \\
\text { 3: Media Assistance: SMILE Videotape } \\
\text { Program, } 35 \text { min, } 41 \text { low intensity exercises. } \\
\text { Attendance records were reviewed and } \\
\text { informal discussions were held to determine } \\
\text { the usefulness of the selected intervention } \\
\text { strategies. }\end{array}$ & $\begin{array}{l}6 \text { months: } 8(57 \%) \text { attended at least } \\
50 \%(26) \text { sessions, } 3(21 \%) \\
\text { attended 90-100\% of sessions. } \\
\text { Weeks 1-6 (2 nurse led sessions) } \\
9(64 \%) \text { attended at least } 50 \% \text { of } \\
\text { sessions, 6(43\%) attended } 90- \\
100 \% \text { of sessions, } 4(28 \%) \text { had } \\
\text { perfect attendance. } \\
\text { Weeks 6-12 (1x nurse 1x peer): } \\
\text { attendance improved, 11(79\%) } \\
\text { members attended at least 50\% of } \\
\text { sessions, } 5(36 \%) \text { attended } 90-100 \% \\
\text { of sessions, } 1(7 \%) \text { had perfect } \\
\text { attendance. } \\
\text { Weeks } 12-\text { end: attendance } \\
\text { declined, } 6(43 \%) \text { attended at least } \\
50 \% \text { of sessions }\end{array}$ \\
\hline $\begin{array}{l}\text { Pre- and post-test } \\
\text { evaluation } \\
\text { Seniors centre }\end{array}$ & $\begin{array}{l}\text { Effects of program on the } \\
\text { health of frail older people. } \\
\text { Effectiveness of } \\
\text { conducting a research } \\
\text { project in which } \\
\text { participants took an active } \\
\text { role in the development } \\
\text { and continuation of } \\
\text { program. }\end{array}$ & $\begin{array}{l}77 ; 73 \text { female; } 72.6 \text { years } \\
\text { multiple chronic conditions } \\
\text { characterised as "frail" } \\
\text { by the centre directors on the } \\
\text { basis of limitations in basic } \\
\text { Activities of Daily Living } \\
\text { (ADL) functions }\end{array}$ & $\begin{array}{l}\text { Development of SMILE videotape: } 30 \text { min } \\
25 \text { basic stretching, range-of-motion, and } \\
\text { flexibility exercises. } 2 x \text { week physical } \\
\text { therapist/nurse, after } 3 \text { weeks a peer leader } \\
\text { would lead segments, at } 6 \text { weeks peer } \\
\text { leaders underwent training, at } 12 \text { weeks peer } \\
\text { leaders took over. } \\
\text { Health outcomes: self-reported mobility, } \\
\text { pain, and psychological well-being. } \\
\text { Participation rates. }\end{array}$ & $\begin{array}{l}\text { 6 weeks Positive health outcomes: } \\
\text { functional mobility, BP } \\
\text { maintenance, and overall well- } \\
\text { being. Participation rates: } \\
\text { Site 1: 95\% @6weeks, 78\% } \\
\text { @3months, 88\% @ 6months, 59\% } \\
\text { @9months } \\
\text { Site 2: 83\% @6weeks, 91\% } \\
\text { @3months, 89\% @6months, 74\% } \\
\text { @9months } \\
\text { Site 3: 69\% @6 weeks, } \\
\text { discontinued program. }\end{array}$ \\
\hline
\end{tabular}


Decline mostly due to healthrelated problems.

Effect of peer leader: made

program more appealing, group

\section{Hickey et al. (1995)}

USA

Pre- and post-test

evaluation

Seniors centre

\section{Hammerback et al.}

(2012)

Evaluation of PALS intervention

131 enrolled in PALS 20052009

USA

Descriptive study

(evaluation)

Telephone support for

people living in the

community

Modra and Black

(1999)

USA

Two-static group

comparison
Effectiveness of low-

for improving functional

ability and psychological

well-being in chronically

impaired older individuals
90; 85 female; 72.6 years.

6 weeks: 77

18 weeks: 32 effects of a peer-led years minimal intervention (MI) MI: 8 (peer leader 72 years) and a professionally EX: 7 conducted exercise (EX) program on functional capacity of senescent intensity physical activity

2x week 30min structured low-intensity

exercise (SMILE). 4 groups 20-25

participants, after 6 weeks a peer leader

would lead segments, final 6 weeks peer

leaders gradually assumed leadership. 8 peer

leaders received training to take over from

professional instructors

Functional Status Index (FSI), 20m walk

time and steps,Life Orientation Test (LOT),

Attitude Toward Aging factorExercise-based self-efficacy scale.

One-on-one telephone support for PALS

program delivered by adult volunteers who were trained in motivational interviewing.

20-30 min calls 2x month for 6 months, $1 x$ month for 6 months. Participant PA level (Rapid Assessment of Physical Activity -

RAPA), Internal study documents, 25 key

PALS stakeholders interviews, 10 Joiner and

10 non joiner interviews -

motivator/barriers, 8 volunteer surveys motivation, experiences, reason for stopping.

MI group spontaneously began a peer-led

walking program at Week $6,4-5 x$ week $30-$
$60 \mathrm{~min}$. Supplied with simple instruction in women. exercise technique at the baseline functional capacity assessments in order for them to perform the tests properly. EX: $60 \mathrm{~min} 3 \mathrm{x}$ week for 12 weeks

PASE, nutrition rating, height, weight, body
6 weeks: Improved self-assessed mobility, flexibility in hand movements, $20 \mathrm{~m}$ walk time and decreases in steps.

18 weeks: Those who continued to exercise maintained improvements in mobility and optimism after 18 weeks.

6 months: RAPA (89): increase 13 to $25 \%$ meeting PA guideline.

Negativity toward telephone only based mentoring.

Volunteers: younger, less diverse, and more educated than the average PALS participant $=$ difficulty with connection.

12 weeks: MI group spontaneously
began a self-initiated walking
program. MI improved on
agility/balance. 880 yard walk and
1 mile walk
EX improved on agility/balance,
muscular endurance, lateral/overall
posture and weight.




\section{Living (walking) in the \\ same neighbourhood}

and retirement/seniors

centres

Waters et al. (2011)

New Zealand

Quasi-experimental

Community facilities

(e.g. local church halls,

bowling clubs)

Evaluate measures of
strength, balance and falls

incidence in participants

attending fall prevention

exercise classes taught by

volunteer peer leaders

(PL), paid professional

(Age

Concern Otago group -

ACO), or a comparison

class (comparison group C).

118; 99 female; 75.5 years; 1 hr per week for 10 weeks. Strength and

older adults with increased

fall risk

PL: $52 ; 83 \%$ female;

$76.5 \pm 7.4$ years

ACO: $41 ; 76 \%$ female;

$77 \pm 6.6$ years

C: $25 ; 68 \%$ female; $78.4 \pm 7.5$

years

\begin{tabular}{ll}
\hline Werner et al. (2014) & $\begin{array}{l}\text { Assess the health related } \\
\text { benefits of ExerStart for }\end{array}$ \\
USA & $\begin{array}{l}\text { Lay Leaders in two } \\
\text { metropolitan areas. }\end{array}$
\end{tabular}

Pre- and post-test

evaluation

Community facilities

(e.g. health care

facilities, affordable

housing, fitness rooms,

senior centres, faith-

based organisations)

432; 382 female; $75 \pm 9.1$

years

metropolitan areas.

Note. MVPA = Mo composition, BP, flexibility, agility/balance,

muscular endurance, coordination, posture,

80 yard walk, 1 mile walk.

balance classes instructed by a professional

(ACO group) or PL. Comparison group (C)

seated exercise classes. After 10 weeks ACO

and $\mathrm{C}$ given option to continue, PL expected

to continue.

Timed Up and Go test, $30 \mathrm{sec}$ chair stand,

functional reach, step touch, Single Leg
Stand, and activities balance confidence.

Falls diaries, PA participation using the

Rapid Assessment of Physical Activity

EX group compliance $78.4 \%$

12 months: $23 \%$ drop out

Functional improvements similar in

PL and ACO from 10 weeks to 12

months, all functional measures sig greater than $\mathrm{C}$.

$27 \%$ decrease in falls for PL compared to $\mathrm{C}$. Continued

participation in strength and balance classes at 12 months greater in PL and ACO compared to C.

ExerStart: 45 min 2x week for 20 weeks, peer-led, low impact exercise program (aerobic endurance, muscular strength,

flexibility, and balance). Received handouts for home exercises. Peer leaders: $8 \mathrm{hr}$

training, training manuals and instructional DVD of exercises. Self-reported: perceived satisfaction with body function, perceived overall health and BMI.

Senior Fitness Test - SFT: chair stand, arm curl, step test, sit and reach, back scratch.
20 weeks: Sig improvement in perceived satisfaction with body function, body mass index,

perceived overall health, and all measures of functional physical fitness (SFT score).

for the elderly, PALS = Physical activity for a Lifetime of Success, BMI = body mass index. 
Table 3 Peer-supported studies and participant characteristics

\begin{tabular}{|c|c|c|c|c|}
\hline $\begin{array}{l}\text { Reference, country, } \\
\text { study design and } \\
\text { setting }\end{array}$ & Study question/aims & $\begin{array}{l}\text { Participants (sample size, } \\
\text { female }(N) \text {, mean age (age } \\
\text { range) }\end{array}$ & Measures & Follow-up and outcomes \\
\hline $\begin{array}{l}\text { Clark et al. (2012) } \\
\text { UK } \\
\text { Longitudinal pre- and } \\
\text { post-test design } \\
\text { Local gymnasium or } \\
\text { fitness facilities }\end{array}$ & $\begin{array}{l}\text { To compare characteristics } \\
\text { of those choosing to join } \\
\text { the peer support (PS) } \\
\text { program versus those who } \\
\text { did not, and to assess the } \\
\text { effect on PA patterns at } 12 \\
\text { months of the PS program. }\end{array}$ & $\begin{array}{l}109 \text { patients with heart } \\
\text { disease who had completed } \\
\text { a program of hospital-based } \\
\text { cardiac rehabilitation } \\
\text { Joined PS: } 79 ; 29 \text { female; } 65 \\
\pm 0.8 \text { years } \\
\text { Didn't join: } 30 ; 5 \text { female; } \\
66.2 \pm 1.6 \text { years }\end{array}$ & $\begin{array}{l}\text { PS program offered to patients who had } \\
\text { completed a } 12 \text { week cardiac rehabilitation } \\
\text { ( } 2 \text { x week supervised exercise, smoking } \\
\text { cessation counselling, healthy eating and } \\
\text { weight, and psychological wellbeing via risk } \\
\text { factor counselling and group-based health } \\
\text { education). } \\
\text { PA levels measured using 7-Day Physical } \\
\text { Activity Recall questionnaire. } \\
\text { The Social Support in Exercise Survey } \\
\text { Subset wore pedometers as objective } \\
\text { measure of PA. }\end{array}$ & $\begin{array}{l}12 \text { months: those who joined tended } \\
\text { to be older and female. } \\
\text { Those who joined PS had similar } \\
\text { levels of PA } 12 \text { months after } \\
\text { cardiac rehab program whereas } \\
\text { those who didn't join had a decline } \\
\text { in PA min per week. }\end{array}$ \\
\hline $\begin{array}{l}\text { Iliffe et al. (2014) } \\
\text { UK }\end{array}$ & $\begin{array}{l}\text { Examine if the two } \\
\text { exercise programs were } \\
\text { effective in increasing } \\
\text { levels of PA } 12 \text { months } \\
\text { after each prooram ended }\end{array}$ & $\begin{array}{l}38 \text { PM } \\
\text { Exercisers: } 1256 ; 62 \% \\
\text { female; } 73 \text { years } \\
\text { FaME: } 387 \\
184 \text { all data }\end{array}$ & $\begin{array}{l}24 \text { weeks } \\
\text { Group } 1 \text { Class-based exercise [Falls } \\
\text { Management Exercise (FaME) programme]: } \\
\text { 1hr weekly classes, 30min 2x week home }\end{array}$ & $\begin{array}{l}12 \text { months: MVPA ( }>150 \\
\text { min/week) increased baseline to } 12 \\
\text { months after intervention: FaME } 40 \\
\text { to } 49 \%(\sim 15 \text { min extra), OEP } 41 \text { to }\end{array}$ \\
\hline RCT & & OEP: 411 & Group 2 Home-based exercise [Otago & FaME and UC. Sig reduction in \\
\hline $\begin{array}{l}\text { Community centres } \\
\text { and home-based }\end{array}$ & & $\begin{array}{l}178 \text { all data } \\
\text { Usual Care: } 458 \\
210 \text { all data }\end{array}$ & $\begin{array}{l}\text { Exercise Programme (OEP)]: supported by } \\
\text { PM (home visits and phone calls) 30min } \\
>3 x w e e k \text { and walking 30min }>2 x \text { week. } \\
\text { Group } 3 \text { Usual care.Functional assessments } \\
\text { of balance and falls risk (including the timed } \\
\text { up and go), the incidence of falls, fear of } \\
\text { falling, quality of life, social networks and } \\
\text { self-efficacy. } \\
\text { Economic evaluation including participant } \\
\text { and NHS costs was embedded in the clinical } \\
\text { trial. }\end{array}$ & $\begin{array}{l}\text { falls rate for FaME compared to } \\
\text { UC. PASE: sig benefit for FaME } \\
\text { compared to UC also perceptions of } \\
\text { benefits from exercise. Balance } \\
\text { confidence sig improved in FaME } \\
\text { and OEP compared to UC. } \\
\text { Participants in FaME/OEP were } \\
\text { more positive about exercise at } \\
\text { follow-up. No changes in } \\
\text { health/wellbeing. FaME is more } \\
\text { expensive than OEP delivered with } \\
\text { PMs. }\end{array}$ \\
\hline
\end{tabular}




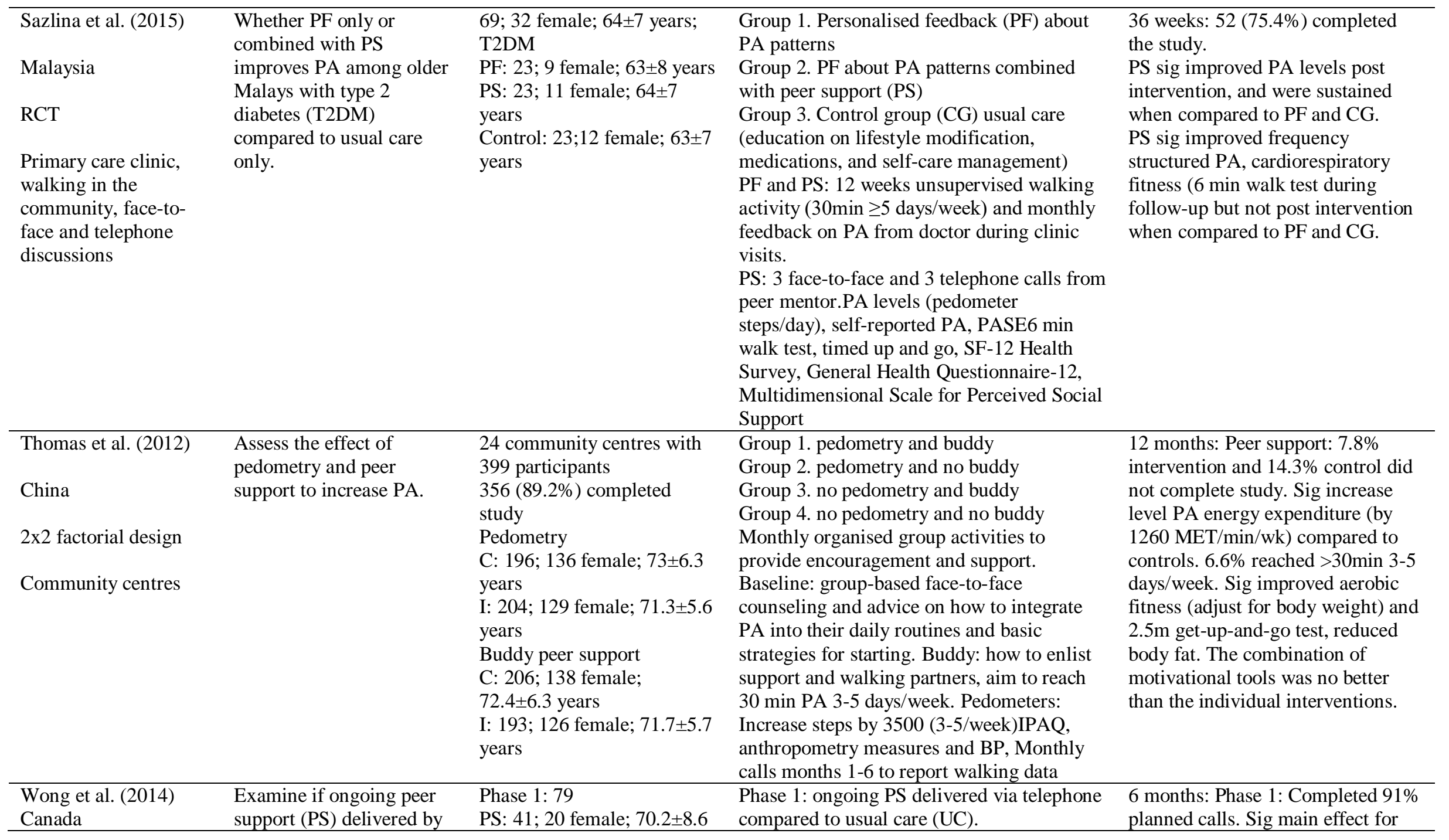




\begin{tabular}{lll}
\hline \multirow{2}{*}{ Two phase RCT } & telephone following & years \\
& pulmonary rehabilitation & UC: $38 ; 19$ female; \\
Telephone-based & (PR) assisted chronic & $65.7 \pm 10.5$ years \\
support and pulmonary & disease (COPD) patients to & PS: $57 ; 30$ female; $69 \pm 9.8$ \\
rehabilitation clinic & maintain health outcomes. & years \\
& & RT: $54 ; 21$ female; $70 \pm 9.5$ \\
& years \\
& UC: $57 ; 30$ female; $69.8 \pm 9$ \\
& years \\
& COPD patients who had \\
& completed PR
\end{tabular}

Phase 2: PS (structured and detailed script), respiratory therapists (RT) or UC.

8 calls over 6 months. PR: 2 hrs supervised

group exercise and $1 \mathrm{hr}$ group classroom

education $2 \mathrm{x}$ week for 8 weeks or $3 \mathrm{x}$ week

for 6 weeks. Developed post program

exercise plan (3-5 days/week)St. George's

Respiratory Questionnaire (SGRQ) - health

related quality of life including subscales:

symptoms, activity and impact, 6 minute

walk test. , full lung function (FEV1\%,

FVC\% and FEV1/FVC ratio), co-morbidity

profile, and medical research council (MRC)

dyspnea scale time for total SGRQ scores and 6MWT, no b/w group differences.

Phase 2: PS completed

$75 \%$ of planned calls, RT $87 \%$.

Sig main effect for time for total

SGRQ scores and 6MWT, no b/w group differences. 6MWT distance improved pre to post, but sig

decline from post to 6 months (6 months still sig greater than pretest).

Note. $\mathrm{PA}=$ physical activity, PASE = physical activity scale for the elderly, FaME = Falls Management Exercise program, OEP = Otago Exercise Programs, $\mathrm{PM}=$ peer mentors, NHS = National Health Service, $\mathrm{PF}=$ personalised feedback, $\mathrm{PS}=$ peers support, $\mathrm{CG}=$ control group, $\mathrm{BP}=\mathrm{blood}$ pressure, $\mathrm{MET}=$

Metabolic Equivalent, RCT = randomised controlled trial, PR = pulmonary rehabilitation, UC $=$ usual care, $\mathrm{RT}=\mathrm{Respiratory}$ Therapist, IPAQ = International Physical Activity Questionnaires. 
Table 4 Quality of RCTs (on-line supplementary only)

\begin{tabular}{|c|c|c|c|c|c|c|}
\hline Study & $\begin{array}{c}\text { Sequence } \\
\text { generation }\end{array}$ & $\begin{array}{c}\text { Allocation } \\
\text { concealment }\end{array}$ & Blinding & $\begin{array}{c}\text { Incomplete outcome } \\
\text { data }\end{array}$ & $\begin{array}{c}\text { Selective outcome } \\
\text { reporting }\end{array}$ & $\begin{array}{c}\text { Free of other } \\
\text { bias }\end{array}$ \\
\hline Buman et al. (2011) & + & $?$ & $?$ & + & + & + \\
\hline Dorgo et al. (2011) & $?$ & $?$ & $?$ & + & + & $?$ \\
\hline Dorgo, King, et al. (2009) & $?$ & $?$ & $?$ & + & + & + \\
\hline Dorgo, Robinson, et al. (2009) & $?$ & $?$ & $?$ & + & + & + \\
\hline Iliffe et al. (2014) & + & + & $?$ & + & + & + \\
\hline Sazlina et al. (2015) & + & + & + & + & + & + \\
\hline Thomas et al. (2012) & + & + & $?$ & + & + & $?$ \\
\hline Wong et al. (2014) & $?$ & $?$ & $?$ & + & + & + \\
\hline
\end{tabular}

Note. Bias was scored as low risk (+), or high risk (-) or unclear (?) Higgins et al. (2011). 
Table 5 Quality of non-randomised studies (on-line supplementary only)

\begin{tabular}{lc}
\hline Study & Quality Score (\%) \\
\hline Barker et al. (2016) & 77 \\
Clark et al. (2012) & 95 \\
Dorgo et al. (2013) & 96 \\
Grove and Spier (1999) & 55 \\
Hickey et al. (1996) & 60 \\
Hickey et al. (1995) & 75 \\
Hammerback et al. (2012) & 85 \\
Modra and Black (1999) & 77 \\
Waters et al. (2011) & 85 \\
Werner et al. (2014) & 100 \\
\hline
\end{tabular}




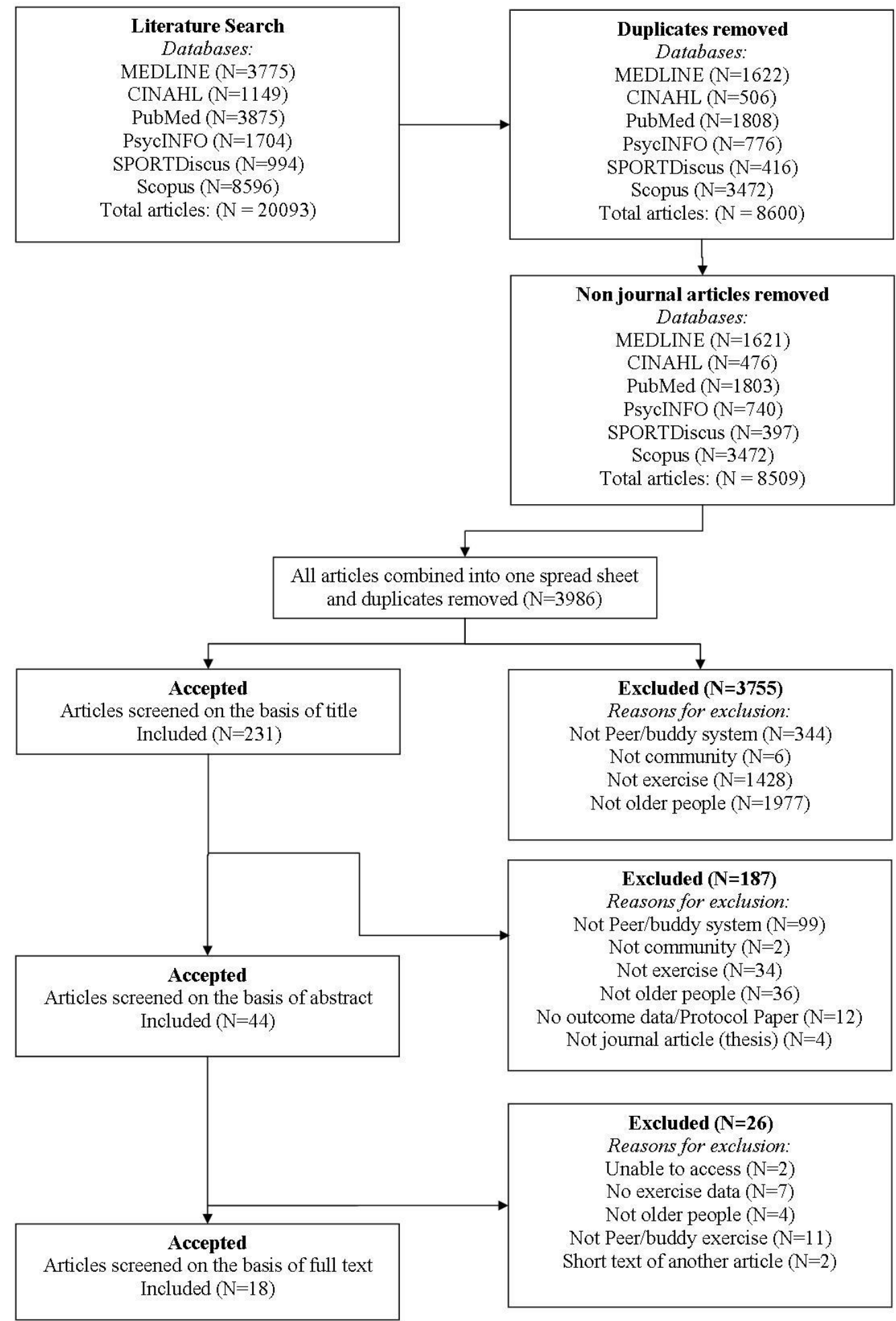

Figure 1. Study selection flow chart 


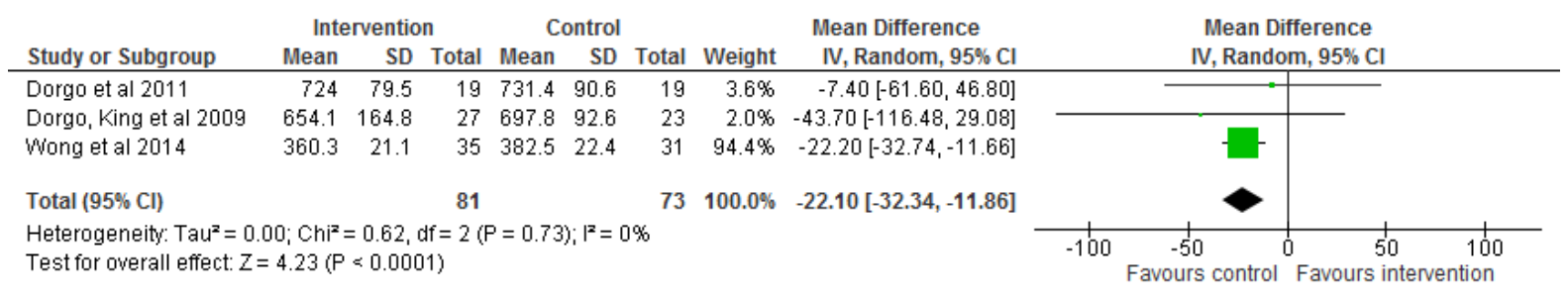

Figure 2. Forest plot of comparison for 6MWT 


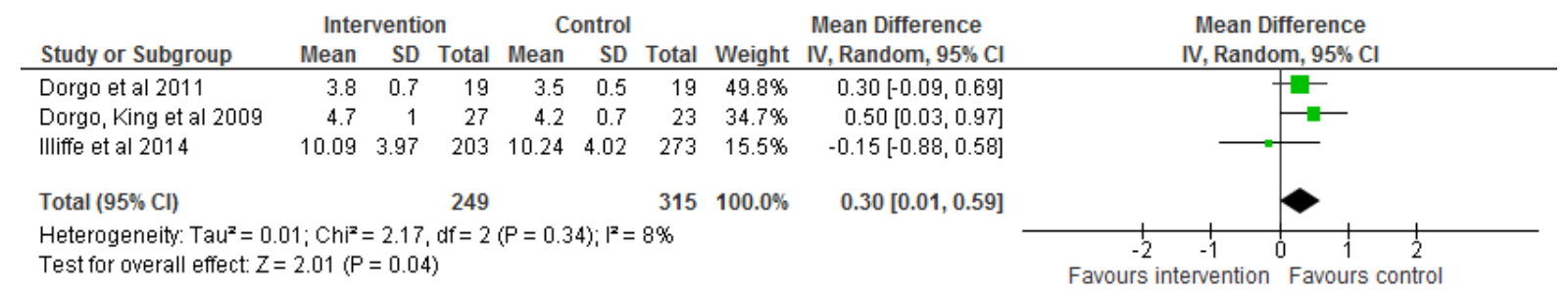

Figure 3. Forest plot of comparison for Timed Up and Go 